\title{
Reversal of Acute Experimental Cerebral Vasospasm by Calcium Antagonism with Verapamil
}

\author{
Richard Leblanc, William Feindel, Lucas Yamamoto, John G. Milton, and Mony M. Frojmovic
}

SUMMARY: Acute vasospasm of the transclivally exposed basilar artery of anesthetised cats was produced by the subarachnoid injection of platelet-rich plasma (PRP) treated with enough adenosine diphosphate (ADP) to induce platelet aggregation and secretion. Vasorelaxation was produced by the topical application of the calcium antagonist verapamil. Changes in the internal diameter of the basilar artery were determined by measuring the blood column diameter from photomicrographs taken sequentially, at 5 minute intervals, through the operating microscope. Changes in blood vessel diameter are expressed as a plus or minus percentage of the pretreatment diameter. Arterial blood pressure and blood gas values were kept in the physiological range for the cat.

The subarachnoid injection of PRP-ADP produced severe constriction of the basilar artery (mean constriction at 5 minutes after injection: $-40.7 \% \pm 2.8 \mathrm{SEM}$ ). Platelet-free plasma, ADP alone and Elliott's A solution had no spasmogenic effect when injected into the subarachnoid space. The topical application of the calcium channel blocker verapamil $(0.1 \mathrm{mg}$ per $\mathrm{kg}) 30 \mathrm{minutes}$ after the injection of PRP-ADP, with the basilar artery still in spasm (mean constriction: $-23 \% \pm 3.5 \mathrm{SEM}$ ), produced prompt and dramatic vasodilation (mean dilation at 5 minutes after application: $+52.7 \% \pm 18.1 \mathrm{SEM}$ ). This spasmolytic effect persisted in a decremental fashion for the 60 minute period of observation, by which time the previously constricted vessel had returned to its normal size. These observations indicate that the platelet fraction of whole blood may be involved in the genesis of acute vasospasm following subarachnoid hemmorhage and that this phenomenon can be readily reversed by calcium antagonism.

RÉSUMÉ: Nous avons produit, grâce à l'injection sous-arachnoidienne de plasma riche en plaquettes (PRP), traité avec adénosine diphosphate (ADP) en concentration suffisante pour induire l'aggrégation et la sécrétion des plaquettes, un vasospasme aigu au niveau de l'artère basilaire exposée chez le chat anesthésié. Une vasorelaxation a été produite par l'application topique d'un antagoniste du calcium, le verapamil. Pour mesurer les modifications du diamètre interne de l'artère basilaire, on s'est servi de photomicrographies séquentielles (au 5 minutes), prises au microscope opératoire, qui permettaient d'évaluer le diamètre de la colonne hématologique. Les modifications dans le diamètre du vaisseau sont indiquées en pourcentage \pm du diamètre prétraitement. La pression artérielle et les gaz sanguins furent maintenus dans des valeurs normales pour le chat.

L'injection sous-arachnoidienne de PRP-ADP a produit une constriction sévère de l'artère basilaire $(-40.7 \% \pm 2.8$ SEM, 5 minutes après l'injection). Le plasma libre en plaquettes, l'ADP seul, la solution d'Elliott A, n'eurent aucun effet spasmogène. L'application topique du verapamil $(0.1 \mathrm{mg}$ par $\mathrm{kg}) 30$ minutes après l'injection de PRP-ADP, alors que l'artère basilaire était encore en spasme $(-23 \% \pm 3.5 \mathrm{SEM})$ causa une vasodilatation prompte et dramatique $(+52.7 \pm 18$ SEM après 5 minutes). Cet effet spasmolytique persista de façon décroissante pour 60 minutes après quoi le vaisseau contracté avait repris son diamètre initial. Ces observations montrent, qu'après une hémorrhagie sous-arachnoïdienne, les plaquettes peuvent être impliquées dans la genèse d'un vaso-spasme aigu et que ce phénomène peut être renversé par un antagoniste du calcium.

Can. J. Neurol. Sci. 1984; 11:42-47

Cerebral vasospasm is a major cause of mortality and morbidity in patients with aneurysmal subarachnoid hemorrhage (SAH) who survive to reach hospital. Platelet produced spasmogens, such as serotonin, prostaglandins and thromboxanes, have been implicated as a cause of experimental and clinical cerebral vasospasm (Yamamoto et al., 1972; Latorre et al., 1974; Peterson et al., 1975; Boullin et al., 1976; Hagen et al. , 1977; Zervas et al., 1979). These substances may produce vasospasm by altering the permeability of the vascular smooth muscle cell to extracellular calcium or to calcium stored in the sarcoplasmic reticulum, permitting its entry into the cell where it becomes available for actin-myosin coupling (Peterson and Leblanc, 1976). With a constant supply of spasmogens the constriction would persist and vasospasm would ensue.

Much enthusiasm has recently been generated for the use of calcium channel blockers in the treatment of angina pectoris secondary to coronary vasospasm (Antman et al., 1976; Johnson et al., 1981; Pepine and Conti, 1981). Preliminary reports attest to the usefulness of these agents in the treatment of experimental and clinical cerebral vasospasm and stroke (Peterson et al., 1969; Allen and Bahr, 1979; Allen et al., 1983; Auer et al., 1981; Brandt et al., 1979; Edvinsson et al., 1979; Takagi et al., 1979; Brandt, 1980; Cohen and Allen, 1980; Nagai et al., 1980; Brandt et al., 1981; Gaab et al., 1982; White et al., 1982; Allen et al.,

From the Cone Laboratory for Neurosurgical Research, Montreal Neurological Institute, and Department of Physiology (Dr. Frojmovic), McGill University, Montreal, Quebec, Canada 
1983). This study documents the reversal of acute vasospasm, produced by platelet-rich plasma (PRP) activated to aggregate and release platelet contents by treatment with ADP, by the topical application of the calcium channel blocker verapamil.

\section{Materials ANd Methods}

Eleven male and female mongrel cats were anesthetised with intraperitoneal pentobarbital, 30-35 mg per $\mathrm{kg}$, and were given atropine, $0.04 \mathrm{mg}$ per $\mathrm{kg}$ intramuscularly. A tracheostomy was performed and the tracheostomy tube was connected to a Harvard Small Animal Ventilator which was adjusted to assure constant arterial blood gas values. Catheterization of the femoral artery and vein permitted continuous monitoring of arterial blood pressure and blood gases and the intravenous administration of pentobarbital as required to maintain anesthesia. Prior to any intravenous infusion, $4.5 \mathrm{cc}$ of venous blood was withdrawn for the production of platelet-rich plasma.

The transclival exposure of the basilar artery was performed by a method previously described (Kapp et al., 1968; Echlin, 1971; Peterson et al., 1975). The dura was elevated using the operating microscope. The arachnoid membrane was left intact and kept moist by intermittent application of Elliot's A solution (mean $\mathrm{pH}$ 6.507). Arterial constriction was produced by injecting $0.4 \mathrm{cc}$ of PRP and ADP, prepared as described below, with a number 27 needle and a tuberculin syringe. Vasodilatation was produced by covering the arachnoid membrane with $0.4 \mathrm{cc}$ of verapamil (mean $\mathrm{pH}$ 6.609; $0.1 \mathrm{mg}$ per $\mathrm{kg}$ ) for 5 minutes.

Initial photographs were taken 30 to 60 minutes after the elevation of the dura and immediately before treatment with PRP-ADP. Photographs were again taken at 5 minute intervals after the subarachnoid injection of PRP-ADP or its controls, for a period of $\mathbf{3 0}$ minutes. At that time, verapamil was applied to the arachnoid membrane and its effects documented in a similar manner for a period of up to 60 minutes, at which time the experiment was repeated. The operative field was dried using a microsuction device before each photographic exposure and was covered with Elliot's A solution after each photograph had been taken. The photographic slides were projected at constant magnification with a $35 \mathrm{~mm}$ slide projector. The blood column diameter within the basilar artery was measured at 3 or 4 points along its length using a millimeter ruler. This method of quantifying changes in the inner diameter of cerebral blood vessels is widely used and has been found to be accurate and reproducible. (Kappet al., 1968; Echlin, 1971; Peterson et al., 1973a; Peterson et al., 1975). The changes in the blood column diameter produced

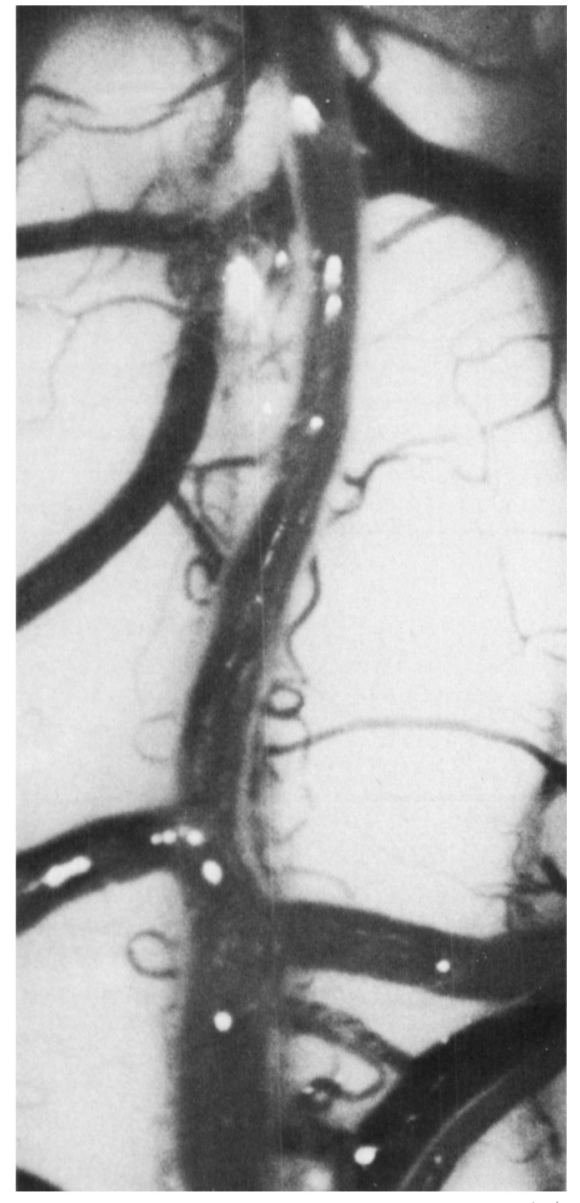

(a)

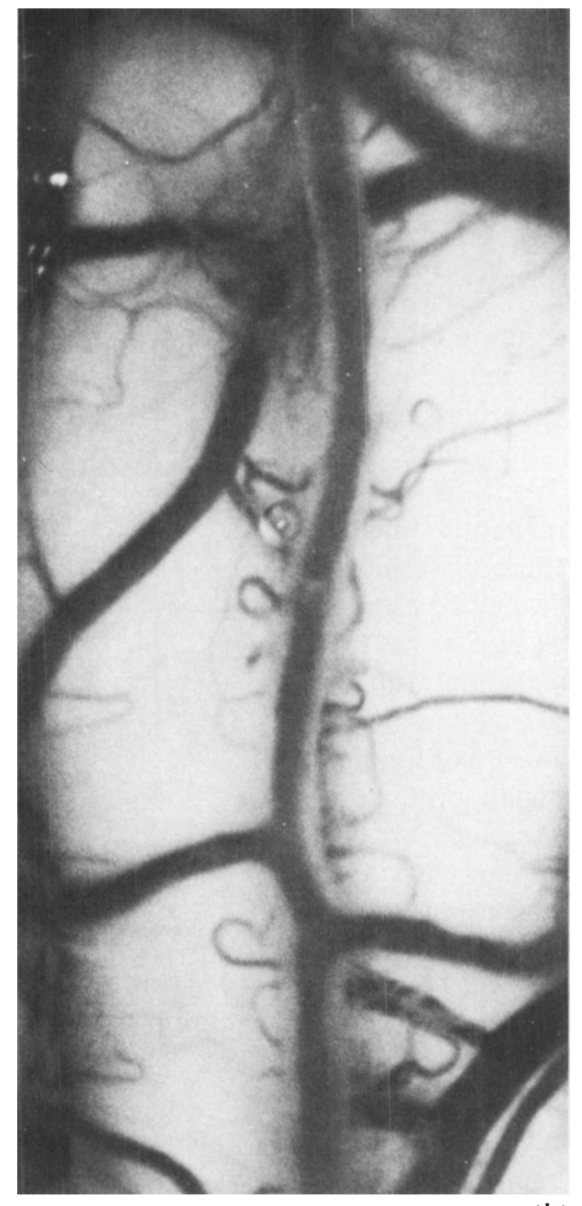

(b)

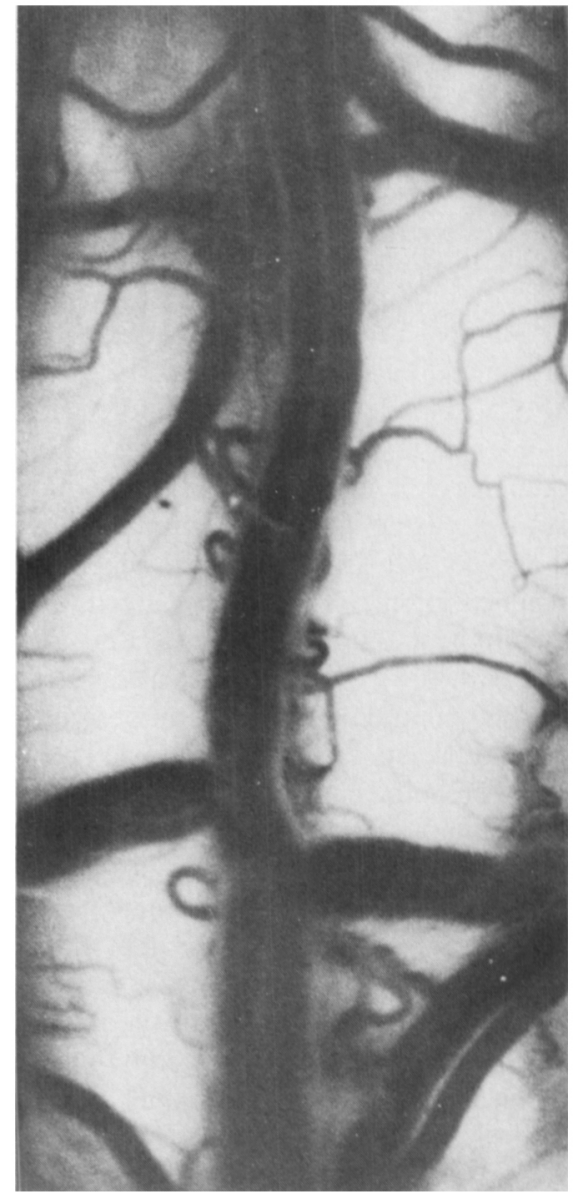

(c)

Figure I - (a) Basilar artery of the cat immediately before the subarachnoid injection of PRP-ADP

(b) The same vessel 10 minutes after the subarachnoid injection of PRP-ADP. demonstrating vasoconstriction.

(c) The same vessel, 5 minutes after the application of verapamil. There is marked vasodilatation. 
by treatment with PRP-ADP and verapamil are expressed as negative (vasoconstriction) or positive (vasodilation) percentage changes of the initial control diameter which is taken to be the blood column diameter at 30 to 60 minutes after the elevation of the dura, prior to any treatment, and is expressed as $0 \%$. Statistical analysis was performed using the student $t$ test for the comparison of 2 means.

PRP was prepared by mixing $0.5 \mathrm{cc}$ of a $3.8 \%$ solution of sodium citrate with $4.5 \mathrm{cc}$ of whole autogenous venous blood in a glass tube. The mixture was allowed to sediment by force of gravity for 2 hours (Marcinkiewicz et al., 1978). The PRP was verified on one occasion to contain 300,000 platelets per microliter. Just prior to the subarachnoid injection the platelets were stimulated to aggregate by mixing $0.4 \mathrm{cc}$ of the PRP with 25 micromolar of ADP in a Born aggregometer for one minute. Visible aggregates were seen in all cases.

Platelet-free plasma (PFP) was prepared after the method of Milton and co-workers (1978) by mixing $2.25 \mathrm{cc}$ of whole venous blood with $0.25 \mathrm{cc}$ of $3.8 \%$ sodium citrate in a plastic tube and centrifuging at 1000 RPM (110G) for 15 minutes at room temperature. The supernatant was centrifuged at $4300 \mathrm{rpm}$ for 15 minutes at room temperature. The new supernatant was centrifuged at $30,000 \mathrm{rpm}$ for 15 minutes at $4^{\circ} \mathrm{C}$. The final supernatant was incubated at $37^{\circ} \mathrm{C}$ until ready for injection into the SAS, approximately 30 minutes after its preparation. The absence of platelets was verified in all cases. Twenty-five micromolar of ADP acted as a control for the ADP used for platelet aggregation. $0.04 \mathrm{cc}$ of Elliott's A solution served as a control for the volume of the platelet aggregate injected into the SAS.

\section{RESULTS}

Platelet-free plasma and ADP, Elliot's A solution or ADP alone had no significant vasoconstrictive effects on the basilar artery. Platelet-rich plasma and ADP produced prompt vasoconstriction of the basilar artery that attained a maximum at 5 minutes after injection (mean constriction: $-40.73 \% \pm 2.84$ SEM) and persisted for the 30 minute observation period (mean constriction: $-23.04 \% \pm 3.51 \mathrm{SEM}$ ). At that time, the topical application of verapamil produced rapid and dramatic vasorelaxation of the blood vessels (mean dilatation at 5 minutes: $+52.74 \% \pm 18.14 \mathrm{SEM}$ ) which persisted in a decremental fashion for the 60 minute observation period, at which time the mean dilation was $6.78 \% \pm 7.52 \mathrm{SEM}$ (Table 1, Figure 1 and Figure 2). The reinjection of PRP-ADP, however, again produced vasoconstriction of a severity similar to that produced by the first injection. Verapamil did not, therefore, prevent vasoconstriction following a second injection of PRP-ADP. Reapplication of verapamil did produce prompt and dramatic reversal of the vasoconstriction produced by the second injection of PRPADP, in a manner similar to the first application of verapamil (Table 2, Figure 3 ). The vasodilation produced by verapamil is not ascribed to its $\mathrm{pH}$ (mean $\mathrm{pH}: 6.609$ ) because application of Elliot's A solution (mean pH: 6.507) had no such effect.

Slight pial or subarachnoid bleeding was incurred in some animals with the injection of the PRP-ADP. In 2 animals this was felt to be of a significant magnitude and these cases are analysed separately. In these 2 cases subarachnoid hemorrhage was produced by the nicking of a side branch and produced spasm, of a similar magnitude and time course as that produced
Table 1: Effects of a first treatment with PRP-ADP and verapamil on the diameter of the basilar artery

\begin{tabular}{rlcc}
\hline \hline Time (min) & $\mathbf{n}$ & $\begin{array}{c}\text { PRP-ADP } \\
\text { \% Change (SEM) }\end{array}$ & $\begin{array}{c}\text { Verapamil } \\
\text { \% Change (SEM) }\end{array}$ \\
\hline & & & \\
5 & 8 & $-40.73(2.84)$ & \\
10 & 8 & $-39.20(3.15)$ & \\
15 & 6 & $-31.07(3.17)$ & \\
20 & 7 & $-29.19(2.9)$ & \\
25 & 8 & $-24.98(3.59)$ & \\
30 & 7 & $-23.04(3.51)$ & \\
35 & 7 & & $+52.74(18.14)$ \\
40 & 8 & & $+49.90(17.06)$ \\
45 & 7 & & $+51.81(14.54)$ \\
50 & 7 & & $+49.42(14.69)$ \\
55 & 8 & & $+45.94(15.19)$ \\
60 & 8 & & $+14.54(15.26)$ \\
75 & 2 & & $+6.78(1.78)$ \\
90 & 4 & & \\
& & & \\
\hline
\end{tabular}

\footnotetext{
$\mathrm{n}=$ number of observations

SEM $=$ standard error of the mean

PRP = platelet-rich plasma

ADP = adenosine diphosphate
}

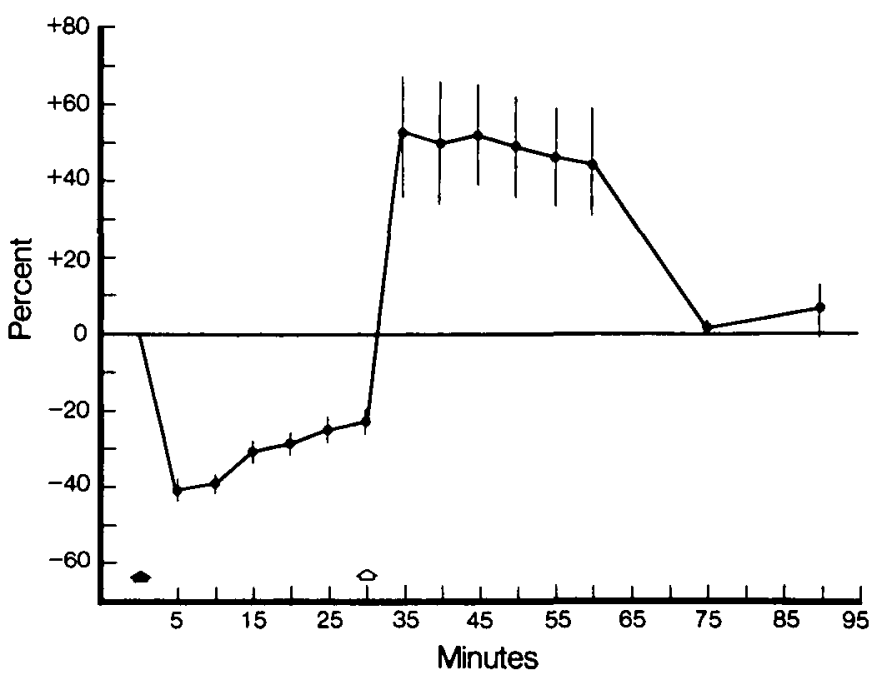

Figure $2-$ Effects (mean and SEM) of the subarachnoid injection of PRP. $A D P$ (closed arrow) and of the topical application of verapamil (open arrow) on the basilar artery of the cat. The negative percentages indicate vasoconstriction and the positive percentages indicate vasodilatation. Vasoconstriction is produced by the injection of PRP-ADP and persists until it is reversed by the application of verapamil.

by PRP-ADP, which was readily reversed with verapamil (Table 3). A statistically insignificant increase in the mean arterial blood pressure (MABP) was noted at 5 and 30 minutes after the subarachnoid injection of PRP-ADP (Table 4). This was not seen with verapamil. There were no significant changes in the $\mathrm{pCO}_{2}$ values during the course of the experiments (Table 5). 
Table 2: Effects of PRP-ADP and verapamil on the dlameter of the basilar artery 60 minutes after a prior application of verapamil

\begin{tabular}{cccc}
\hline Time (min) & $\mathbf{n}$ & $\begin{array}{c}\text { PRP-ADP } \\
\text { \% Change (SEM) }\end{array}$ & $\begin{array}{c}\text { Verapamil } \\
\text { \% Change (SEM) }\end{array}$ \\
\hline 5 & 6 & $-29.52(19.17)$ & \\
10 & 6 & $-30.49(11.74)$ & \\
15 & 6 & $-34.64(12.70)$ & \\
20 & 5 & $-29.23(12.60)$ & \\
25 & 6 & $-30.74(14.88)$ & \\
30 & 6 & $-30.44(12.20)$ & \\
35 & 6 & & $+29.53(18.38)$ \\
40 & 6 & & $+31.68(27.43)$ \\
45 & 5 & & $+39.64(41.51)$ \\
50 & 5 & & $+25.90(24.52)$ \\
55 & 4 & & $+24.01(20.41)$ \\
60 & 4 & & $+1.63(10.67)$ \\
75 & 1 & & -11.60 \\
90 & 1 & & \\
\hline
\end{tabular}

PRP = platelet-rich plasma

ADP $=$ adenosine diphosphate

Table 3: Effects of subarachnoid hemorrhage and verapamll on the dlameter of the basilar artery

\begin{tabular}{|c|c|c|c|}
\hline Time (min) & $\mathbf{n}$ & $\begin{array}{c}\text { SAH } \\
\% \text { Change (SEM) } \\
\end{array}$ & $\begin{array}{c}\text { Verapamil } \\
\% \text { Change (SEM) } \\
\end{array}$ \\
\hline 5 & 2 & $-35.34(14.66)$ & \\
\hline 10 & 2 & $-38.95 \quad(2.94)$ & \\
\hline 15 & 2 & $-44.18(1.18)$ & \\
\hline 20 & 2 & $-35.40 \quad(5.53)$ & \\
\hline 25 & 2 & $-32.35 \quad(2.65)$ & \\
\hline 30 & 2 & $-28.89(3.50)$ & \\
\hline 35 & 2 & & $+63.98(12.57)$ \\
\hline 40 & 2 & & $+74.30(16.28)$ \\
\hline 45 & 2 & & $+59.29(29.88)$ \\
\hline 50 & 2 & & $+55.58(18.74)$ \\
\hline 55 & 1 & & +57.89 \\
\hline 60 & 1 & & +47.36 \\
\hline
\end{tabular}

SAH = subarachnoid hemorrhage

PRP = platelet-rich plasma

ADP $=$ adenosine diphosphate

Table 4: Values of mean arterial blood pressure during the Initial PRP-ADP and verapamil experiments

\begin{tabular}{|c|c|c|c|c|c|c|}
\hline & \multicolumn{4}{|c|}{ PRP-ADP } & \multicolumn{2}{|c|}{ Verapamil } \\
\hline & $\mathbf{n}$ & Mean & SD & $n$ & Mean & SD \\
\hline $\begin{array}{l}5 \text { min. before } \\
\text { treatment }\end{array}$ & 8 & 138.75 & 23.41 & 8 & 151.75 & 34.51 \\
\hline $\begin{array}{l}5 \text { min. after } \\
\text { treatment }\end{array}$ & 8 & 148.25 & 28.03 & 7 & 155.29 & 42.70 \\
\hline $\begin{array}{l}30 \mathrm{~min} . \text { after } \\
\text { treatment }\end{array}$ & 7 & 156.57 & 32.40 & 8 & 158.00 & 48.87 \\
\hline
\end{tabular}

PRP-ADP = Platelet-rich plasma and adenosine diphosphate SD $=$ Standard Deviation
Table 5: Values of the $\mathrm{pCO}_{2}$ during the initial PRP-ADP and verapamil experiments

\begin{tabular}{|c|c|c|c|c|c|c|}
\hline & \multicolumn{4}{|c|}{ PRP-ADP } & \multicolumn{2}{|c|}{ Verapamil } \\
\hline & $\mathrm{n}$ & Mean & SD & n & Mean & $S D$ \\
\hline $\begin{array}{l}5 \text { min. before } \\
\text { treatment }\end{array}$ & 6 & 36.43 & 1.17 & 66 & 36.55 & 2.12 \\
\hline $\begin{array}{l}5 \text { min. after } \\
\text { treatment }\end{array}$ & 4 & 36.75 & 2.08 & 6 & 37.85 & 2.37 \\
\hline $\begin{array}{l}30 \mathrm{~min} \text {. after } \\
\text { treatment }\end{array}$ & 6 & 36.55 & 2.12 & 4 & 36.60 & 1.57 \\
\hline
\end{tabular}

PRP-ADP = Platelet-rich plasma and adenosine diphosphate

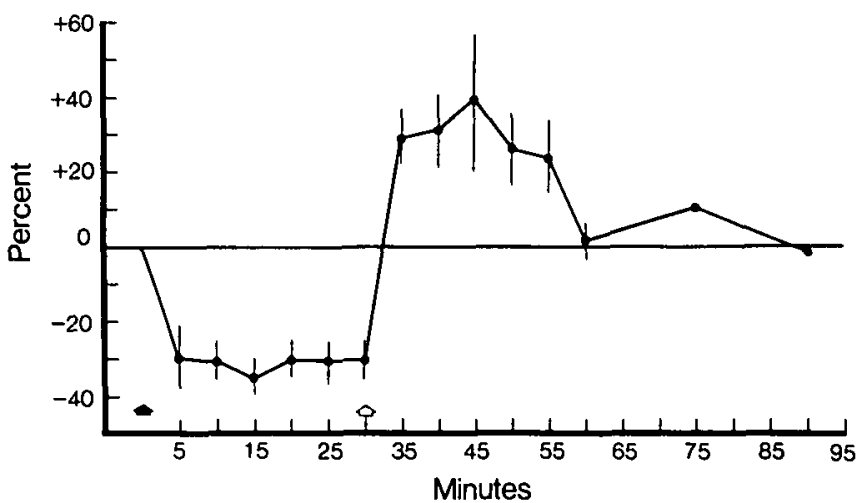

Figure 3 - Effects (mean and SEM) of the subarachnoid injection of PRP. $A D P$ (closed arrow) and of verapamil (open arrow) on the basilar artery of the cat, when PRP-ADP is injected 60 minutes after a treament with verapamil. Negative percentages indicate vasoconstriction and positive percentages indicate vasodilatation. Vasoconstriction is produced despite prior treatment with verapamil, but is readilv reversed bs the reapplication of verapamil.

\section{Discussion}

Despite more than twenty years of laboratory experimentation and numerous trials of treatment of the clinical syndrome with a variety of drug regimens (Sundt et al., 1973; Zervas et al., 1979; Flamm, 1980) there is no universally effective pharmacological treatment of cerebral vasospasm. One of the major factors responsible for this is the difficulty of producing a reliable model for the production of delayed vasospasm that mimics the clinical condition. Most of the advances in our understanding of vasospasm, therefore, have come from experimentation on acute experimental models. The present study uses Echlin's model (Echlin, 1971) as modified by Kapp and his co-workers (Kapp et al., 1968) to insure reproducibility by stabilizing physiological conditions. We have further refined this model so as to avoid the mechanical trauma incurred with the resection of the arachnoid membrane and to eliminate the risk of drying of the blood vessels, shown by Kapp et al. to have a potent vasoconstrictive effect (Kapp et al., 1968). This is accomplished by leaving the arachnoid membrane intact and injecting the spasmogen directly into the SAS with a fine needle. The presence 
of a relatively intact arachnoid membrane also prevents any ambient blood from coming into direct contact with the vessels under investigation. Besides eliminating these potential sources of artifactual vasoconstriction, the injection of the spasmogen into the SAS more closely reproduces the acute phase of SAH.

The subarachnoid injection of PRP-ADP and subarachnoid hemorrhage produced by nicking of a side branch of the basilar artery produced a statistically insignificant elevation of the mean arterial blood pressure (MABP). Espinosa and co-workers noted a $25 \%$ increase in MABP in 50 to $70 \%$ of their monkeys during the creation of chronic experimental SAH (Espinosa et al., 1982). They found no relationship between this increase in MABP and the development of vasospasm at any time after $\mathrm{SAH}$. In our experiments the increase in MABP may represent a reflex response to brainstem ischemia secondary to the constriction of the basilar artery. The choice of ADP-activated PRP to cause acute experimental vasospasm is pertinent in 3 ways: (1) Platelet aggregation has been noted to be increased in patients with spontaneous coronary artery vasospasm (Robertson et al., 1980). By analogy abnormally increased platelet aggregation may be a factor in the genesis of cerebral vasospasm. (2) The platelet fraction of whole blood contains a number of vasoactive compounds which may be involved in the genesis of the acute phase of cerebral vasospasm. (3) Most of the putative spasmogens associated with platelets are produced by brain tissue (Wolfe, 1981). Endogenous biosynthesis of PG-E $E_{2}, P G-F_{2 \alpha}$, and PG-D has been demonstrated in the cat cerebral cortex, hippocampus and cerebellum and synthesis of these compounds and of thromboxane $B_{2}$ has been demonstrated in the rat and guinea pig cerebral cortex (Wolfe, 1981). Predominant amongst these, in the cerebral cortex of most of the species studied, is PG- $F_{2 \alpha}$, which has been demonstrated to be a potent vasoconstrictor. Prostaglandins $\mathrm{F}-2 \alpha$ and $\mathrm{E}_{2}$ are seen in increased amounts in the CSF of patients with subarachnoid hemorrhage, stroke, meningoencephalitis and following brain surgery, all conditions which are often associated with vasospasm (Wolfe and Mamer, 1974; Carasso et al., 1977; Hagen et al., 1977).

The final common pathway leading to vasospasm must involve calcium-mediated actin and myosin coupling (Peterson and Leblanc, 1976). Interference with this process by chelation with EDTA or by promotion of cyclic-AMP-mediated calcium ion sequestration has been demonstrated to reverse experimentally induced vasospasm (Peterson et al, 1969; Peterson et al, 1973a; Peterson et al., 1973b; Peterson et al., 1975). Our experiments document that the topical application of a calcium antagonist results in consistent and dramatic reversal of acute experimental vasospasm. They also demonstrate that the effects of this drug are transient, and that vasospasm can be induced in the basilar artery 60 minutes after treatment with verapamil. This indicates that as long as blood vessels are exposed to spasmogens, a continuous supply of calcium blockers may be required to assure ongoing antagonism of their action. This may limit the usefulness of verapamil itself, given systemically, in view of its known hypotensive effects (Lewis, 1980). Nonetheless, calcium channel blockers have marked spasmolytic properties and therefore show promise for the treatment of cerebral vasospasms (Allen et al., 1983).

\section{ACKNOWLEDGMENT}

We are grateful to Dr. Leon S. Wolfe, head of the department of neurochemistry, of the Montreal Neurological Institute and McGill
University for fruitful discussions and advice. We are also grateful to Mrs. Janet Arts for her able technical assistance. This work was supported by the Medical Research Council of Canada and by the William Cone Laboratory for Neurosurgical Research.

\section{REFERENCES}

Antman, E., Muller, J., Goldberg, S. et al., (1980). Nifedipine therapy for coronary artery spasm. N. Engl. J. Med. 302:1269-1273.

Allen, G.S., Bahr, A.L., (1979). Cerebral arterial spasm: Part 10. Reversal of acute and chronic spasm in dogs with orally administered nifedipine. Neurosurg. 4:43-47.

Allen, G.S., Ahn, H.S., Preziosi, T.J. et al., (1983). Cerebral arterial spasm - A controlled trial of nimodipine in patients with subarachnoid hemorrhage. N. Eng. J. Med. 308:619-624.

Auer, L.M., Ito, A., Suzuki, A., Ohta, H., (1981). Topical administration of nimodipine for treatment of cerebral vasospasm after acute aneurysm surgery. Presented at the International Symposium on Cerebrovascular Diseases: New Trends in Surgical and Medical Aspects. Gardone Riviera (Garda Lake, Italy) July 2-4.

Boullin, D.J., Mohan, J., Grahame-Smith, D.G., (1976). Evidence for the presence of a vasoactive substance (possibly involved in the aetiology of cerebral arterial spasm) in cerebrospinal fluid from patients with subarachnoid haemorrhage. J. Neurol. Neurosurg. Psychiatry 39:756-766.

Brandt, L., (1980). Effects of a calcium antagonist on cerebrovascular smooth muscle in vitro and in vivo. In Cerebral Arterial Spasm: Proceedings of the Second International Workshop. Baltimore, Williams \& Wilkins.

Brandt, L., Anderson, K-E., Edvinsson, L., Ljunggren, B., (1981). Effects of extracellular calcium and of calcium antagonists on the contractile responses of isolated human pial and mesenteric arteries. J. Cereb. Blood Flow Met 1:339-347.

Brandt, L., Anderson, K-E., Bengtsson, B. et al., (1979). Effects of nifedipine on pial arteriolar calibre: An in vivo study. Surg. Neurol. 12:349-352.

Carasso, R.L., Vardi, J., Rabay, J.M., Zor, U., Streifler, M., (1977). Measurement of prostaglandin $\mathrm{E}_{2}$ in cerebrospinal fluid in patients suffering from stroke. J. Neurol. Psychiatr. 40: 967-969.

Cohen, R.J., Allen, G.S.: Cerebral arterial spasm (1980). The role of calcium in in vitro and in vivo analysis of treatment with nifedipine and nimodipine. In Cerebral Arterial Spasm: Proceedings of the Second International Workshop. Baltimore, Williams \& Wilkins.

Echlin, F., (1971). Experimental vasospasm, acute and chronic, due to blood in the subarachnoid space. J. Neurosurg. 35:646-656.

Espinosa, F., Weir, B., Boisvert, D., Overton, T., Castor, W., (1982). Chronic cerebral vasospasm after large subarachnoid hemorrhage in monkeys. J. Neurosurg. 57:224-232.

Edvinsson, L., Brandt, L., Andersson, K.E., Bengtsson, B., (1979). Effect of a calcium antagonist on experimental constriction of human brain vessels. Surg. Neurol. 11:327-330.

Flamm, E.S., (1980). Treatment of cerebral vasospasm with aminophylline and isoproterenol. In Cerebral Arterial Spasm: Proceedings of the Second International Workshop. Baltimore, Williams \& Wilkins.

Gaab, M.R., Brawansri, A., Bockhorn, J. et al., (1982). Calcium antagonism: A new therapeutic principle in stroke and cerebral vasospasm, rCBF Bull 3:47-51.

Hagen, A.A., Gerber, J.N., Sweeley, C.C., White, R.P., Robertson, J.T., (1977). Levels and disappearance of prostaglandin $F_{2^{\alpha}}$ in cerebral spinal fluid: a clinical and experimental study. Stroke 8:672-675

Johnson, S.M., Mauritson, D.R., Willerson, J.T., Hellis, L.D., (1981). A control trial of verapamil for Printzmetal's Variant Angina. N. Eng. J. Med. 304:862-866.

Kapp, J., Mahaley, M.S., Odon, G.L., (1968). Cerebral Arterial Spasm Part 1: Evaluation of experimental variables affecting the diameter of the exposed basilar artery. J. Neurosurg. 24:331-338.

Lewis, G.R., (1980). Verapamil in the management of chronic hypertension. Clin. Invest. Med. 3:175-177.

Latorre, E., Patrono, C., Fortuna, A., Grossi-Belloni, D., (1974). Role of prostaglandin $F_{2^{\alpha}}$ in human cerebral vasospasm. J. Neurosurg. 41:293-99.

Marcinkiewicz, E., Grodzinska, L., Gryglewski, J., (1978). Platelet aggregation and thromboxane $A_{2}$ formation in cat platelet rich plasma. Pharmacol. Res. Comm. 10:1-12. 
Milton, J.G., Yung, W., Glushak, C., Frojmovic, M.M., (1978). Kinetics of ADP-induced human platelet shape change: Apparent positive cooperability. Can. J. Physiol. Pharmacol. 58:45-52.

Nagai, H., Takagi, T., Kamiya, K., Fukuoka, H., (1980). Effect of vasoactive drugs on late spasm. In Cerebral Arterial Spasm: Proceedings of the Second International Workshop. Baltimore, Williams \& Wilkins.

Pepine, C.J., Conti, R.C., (1981). Calcium blockers in coronary heart disease Part Il. Modern Concepts of Cardiovascular Disease 50:67-72.

Peterson. E.W., Metuzals, J., Johnson, D.H., (1969). The relief of cerebral vasospasm by topically applied ethylene diamine tetraacetic acid (EDTA). Excerpta Med. Int. Congr. Ser. 193:72.

Peterson, E.W., Leblanc, R.. (1976). A theory of the mechanism of cerebral vasospasm and its reversal. The role of calcium and cyclicAMP. Can. J. Neurol. Sci. 3:223-226.

Peterson, E.W., Leblanc, R., Lebel, F., (1975). Cyclic adenosine monophosphate antagonism of prostaglandin induced vasospasm. Surg. Neurol: 4:490-496.

Peterson, E.W., Searle, R., Mandy, F.F., Leblanc, R., (1973a). The reversal of experimental vasospasm by dibutyryl-3',5'-adenosine monophosphate. J. Neurosurg. 39:730-734.

Peterson, E. W., Searle, R., Mandy, F., Leblanc, R., Bosc, M., (1973b). A chronic experimental model for the production of subarachnoid haemmorrhage. Br. J. Surg. 60:316-317.

Robertson, R.M., Robertson, D., Friesinger, G. et al., (1980). Platelet aggregation in peripheral and coronary sinus blood in patients with spontaneous coronary artery spasm. Lancet II: 829-831.

Sundt, T.M. Jr., Onofrio, B.M., Merideth, J., (1973). Treatment of cerebral vasospasm from subarachnoid hemorrhage with isoproterenol and lidocaine hydrochloride. J. Neurosurg. 38:557-560.

Takagi, T., Kamiya, K., Fukuoka, H. et al., (1979). Effects of C.A. antagonists on experimental vasospasm. Cerebral blood flow and metabolism. Acta Neurolog. Scand. (Suppl. 72) 60:486-487.

White, R.P., Cunningham, M.P., Robertson. J.T., (1982). Effects of the calcium antagonist nimodipine on contractile responses of isolated canine basilar arteries induced by serotonin, prostaglandin $F_{2 \alpha}$, thrombin, and whole blood. Neurosurg. 10:344-348.

Wolfe, L.S., Mamer, O.A., (1974). Measurement of prostaglandin $F_{2}$ levels in human cerebrospinal fluid in normal and pathological conditions. Prostaglandins 9:183-92.

Wolfe, L.S., (1981). Prostaglandins and thromboxanes in the nervous system. Seigel. Albers, Agranoff, Katzman (eds.). Basic Neurochemistry, 3rd edition. Little Brown and Co., Boston, pp. 311-320.

Yamamoto, Y.L., Feindel, W., Wolfe, L.S., Katoh, H., Hodge, C.P. (1972). Experimental vasoconstriction of cerebral arteries by prostaglandins. J. Neurosurg. 37:385-97.

Zervas, N.T., Candia, M., Candia, G., Kido, D., Pessin, M.S., Rosoff, C.B., Bacon, W., (1979). Reduced incidence of cerebral ischemia following rupture of intracranial aneurysms. Surg. Neurol. 11:339-344. 